\title{
Variações anatômicas de Laelia purpurata var. cárnea cultivada in vitro sob diferentes intensidades e qualidade spectral de luz
}

\author{
Anatomical variations of Laelia purpurata var. cárnea in vitro cultured under different intensities and \\ spectral quality of light
}

\author{
Jessé Marques da Silva Júnior ${ }^{\mathrm{I}}$ Evaristo Mauro de Castro ${ }^{\mathrm{I}}$ Marcelo Rodrigues $^{\mathrm{I}}$ Moacir PasqualI $^{\mathrm{II}}$ \\ Suzan Kelly Vilela Bertolucci ${ }^{\mathrm{II}}$
}

\section{RESUMO}

Plantas de Laelia purpurata var. cárnea propagadas in vitro e mantidas em sala de crescimento e em casa de vegetação foram submetidas a diferentes intensidades e qualidade espectral de luz, envolvidas com diferentes malhas coloridas: azul, vermelha e preta. Foi observado que a intensidade e qualidade espectral de luz interferiram de forma significativa em todos os parâmetros analisados, aos 120 dias de cultivo. Plantas cultivadas sob malha azul em sala de crescimento e casa de vegetação apresentaram maior espessamento da epiderme na face adaxial (31,73 e 35,46 $\mu \mathrm{m})$, respectivamente, diferindo estatisticamente quando comparado com os demais tratamentos. Foi observado aumento significativo no número de camadas de células do velame em raizes de plantas cultivadas em casa de vegetação, independente da malha de sombreamento, quando comparadas com as de sala de crescimento. Em secções transversais de raizes de plantas cultivadas em casa de vegetação sob malha azul, foi observada maior diferenciação dos tecidos (velame, exoderme, córtex e cilindro vascular).

Palavras-chave: orquídea, propagação in vitro, malhas fotoconversoras, aclimatização.

\section{ABSTRACT}

In vitro propagated orchid (Laelia purpurata var. cárnea) were maintained in a growth chamber in a greenhouse and subjected to different spectral intensities and quality of light, using different colored shade-net (blue, red and black). It was observed that the light intensity and spectral quality influenced significantly all the parameters analyzed at 120 days of cultivation. Plants cultivated under blue color shade net at growth chamber and greenhouse presented higher thickening of epidermis on the adaxial face (31.73 and $35.46 \mu \mathrm{m})$, respectively, and were statistically different when compared with other treatments. It was observed a significant increase in the number of velamen cell layers in plant roots grown in the greenhouse, regardless of the color shade-net used when compared with plants cultivated at growth chamber. It was observed a higher differentiation of tissues (canopy, exodermis, cortex and vascular cylinder) in cross sections plant roots grown in greenhouse under blue shade-net.

Key words: orchid, in vitro propagation, colored shade-nets, acclimatization.

\section{INTRODUÇÃO}

As orquídeas estão entre as plantas ornamentais mais apreciadas e de grande valor comercial. São caracterizadas por sua capacidade de combinação gênica entre variedades. Das sementes que as orquídeas produzem na natureza, a taxa de germinação média é de apenas 4\%. Dessa forma, a cultura de tecidos se destaca como uma técnica que viabiliza a germinação de sementes, possibilitando a obtenção de grande quantidade de mudas em curto espaço de tempo (PASQUAL et al., 2011).

O gênero Laelia encontra-se ameaçado pela intensa destruição de seu habitat no Brasil, pelas mudanças climáticas, tais como temperatura e irradiação, sendo necessário maior investimento em pesquisas para sua conservação e propagação (ÁVILA-DIAZ et al., 2009).

Alguns trabalhos descrevem efeitos marcantes sobre a fotomorfogênese de plantas, seja

IDepartamento de Biologia, Setor de Fisiologia Vegetal, Universidade Federal de Lavras (UFLA), CP 3037, 37200000, Lavras, MG, Brasil. E-mail: marcel.or.7@hotmail.com.*Autor para correspondência.

"Departamento de Agricultura, Setor de Fitotecnia, UFLA, Lavras, MG, Brasil. 
pela iluminação artificial, por coberturas de solo, coberturas e malhas coloridas em casa de vegetação, que modificam a radiação por elas transmitida (ORENSHAMIR et al., 2001; SHAHAK et al., 2004; MARTINS et al., 2009).

Segundo OREN-SHAMIR et al. (2001), a utilização da malha fotoconversora vermelha é capaz de alterar o espectro da luz, reduzindo as ondas azuis, verdes e amarelas, acrescentando as ondas na faixa espectral do vermelho e vermelho-distante. Já a malha azul é capaz de mudar o espectro da luz, reduzindo as ondas na faixa do vermelho, vermelho distante e acrescentando ondas azuis.

A luz é um fator fundamental para as plantas no processo de regulação de seu crescimento e desenvolvimento vegetativo e reprodutivo. As respostas morfofisiológicas das plantas não dependem apenas da presença, atenuação ou ausência da luz, mas também da variação em qualidade luminosa (LARCHER, 2004).

Como descrito na literatura, foram observadas modificações na anatomia foliar de plantas de Dendranthema grandiflorum cv. Rage submetidas a sombreamento por malhas coloridas. Uma vez que a folha é um órgão plástico e sua estrutura interna adapta-se às condições externas do ambiente (BRAGA et al., 2009).

Sabendo que malhas fotoconversoras podem alterar as estruturas anatômicas de plantas. $\mathrm{O}$ objetivo desse trabalho foi avaliar os aspectos morfoanatômicos da folha e raiz da espécie Laelia purpurata var. cárnea cultivada in vitro, em sala de crescimento e casa de vegetação, submetida a diferentes malhas fotoconversoras: azul, vermelho e preto.

\section{MATERIAIS E MÉTODOS}

O experimento foi realizado em Lavras, $\mathrm{MG}$, Brasil a $21^{\circ} 14^{\prime} \mathrm{S}, 45^{\circ} 17^{\prime} \mathrm{W}$ e $918 \mathrm{~m}$ de altitude, entre janeiro e junho de 2009. A sala de crescimento foi acondicionada com fotoperíodo de $16 \mathrm{~h}$, temperatura de $25 \pm 2^{\circ} \mathrm{C}$ e radiação de $52 \mathrm{w} \mathrm{m}^{-2} \mathrm{~s}^{-1}$ (LI-200SA; Li-cor, Lincoln, Nevasca, USA), fornecida por lâmpadas brancas fluorescentes. As condições da casa de vegetação foram temperatura entre $16^{\circ}$ a $20^{\circ} \mathrm{C}$ e fotoperíodo de 12 a $14 \mathrm{~h}$, conforme dados da estação meteorológica de Lavras, e radiação $256 \mathrm{~W} \mathrm{~m} \mathrm{~m}^{-2} \mathrm{~s}^{-1}$ (LI200SA; Li-cor, Lincoln, Nevasca, USA).

Sementes de Laelia purpurata var. cárnea foram germinadas in vitro em meio de cultura MS (MURASHIGE \& SKOOG, 1962) com a metade da concentração dos sais, solidificado com $6 \mathrm{~g} \mathrm{~L}^{-1}$ de ágar, $30 \mathrm{~g} \mathrm{~L}^{-1}$ de sacarose, $\mathrm{pH}$ ajustado para 5,8, e autoclavado a $121^{\circ} \mathrm{Ca} 0,1 \mathrm{~atm}$ por $20 \mathrm{~min}$.
Após três meses da inoculação, período em que as plantas apresentavam cerca de $1 \mathrm{~cm}$ de comprimento, foram transferidas para meio MS

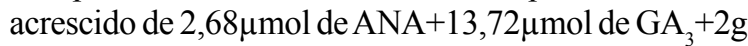
$\mathrm{L}^{-1}$ de carvão ativado $+100 \mathrm{~g} \mathrm{~L}^{-1}$ de polpa de banana nanica, seguido da metodologia descrita anteriormente.

As plantas com $1 \mathrm{~cm}$ foram cultivadas em sala de crescimento e em casa de vegetação nas seguintes condições: 1) expostos diretamente à luz ambiente (controle); 2) malha fotoconversora azul 50\% ; 3) malha fotoconversora vermelha $50 \%$; e 4) malha sombrite preta $50 \%$. Os tratamentos cultivados em sala de crescimento foram dispostos da seguinte forma: expostos à luz ambiente (SC) como controle, sombreados sob malha fotoconversora azul (SCA), sombreados sob malha fotoconversora vermelha (SCV) e sombreados com malha sombrite preta (SCP).

Já os tratamentos cultivados em casa de vegetação foram dispostos em: exposição à luz ambiente (CV) como controle; sombreados sob malha fotoconversora azul 50\% (CVA), sombreados sob malha fotoconversora vermelha $50 \%(\mathrm{CVV})$ e sombreados com malha sombrite preta $50 \%$ (CVP).

Amostras de tecidos foliares e radiculares foram fixadas em F.A.A. 70\% (formaldeído, ácido acético glacial e etanol $70 \%$ ), por $72 \mathrm{~h}$ e armazenadas em etanol 70\% (JOHANSEN, 1940). Foram realizadas secções transversais manuais na região mediana das folhas, e a $4,5 \mathrm{~cm}$ das raízes no sentido ápice-base. Cortes paradérmicos foram realizados apenas em folhas de indivíduos dos dois ambientes. As secções transversais foram coradas com safrablau, enquanto que os paradérmicos com safranina $(0,1 \%$ aquosa). Foram confeccionadas lâminas semipermanentes e observadas em microscópio óptico da marca Olympus e modelo BX60, com câmera digital (Canon A630) acoplada (PEREIRA et al., 2008).

As imagens foram analisadas utilizando o software Imagetool-UTHSCSA para análises de micromorfometria das secções transversais das folhas e raízes. Já nos cortes paradérmicos, foram mensurados os diâmetros polares e equatoriais dos estômatos, assim como a densidade estomática (número de estômatos por $\mathrm{mm}^{2}$ ), após 120 dias de cultivo in vitro (METCALFE \& CHALK 1979).

O delineamento experimental foi inteiramente casualizado, com oito tratamentos e dois ambientes, avaliado em fatorial $(4 \times 2)$, contendo 20 repetições, sendo cada repetição constituída por um frasco com cinco plantas de $1 \mathrm{~cm}$ de comprimento. Os dados foram submetidos à análise de variância e as médias foram comparadas, pelo teste de Tukey, a 5\% de probabilidade, utilizando-se o software estatístico Genes (CRUZ, 1998). 


\section{RESULTADOS E DISCUSSÃO}

Quanto aos aspectos anatômicos, o ambiente de cultivo e as malhas coloridas promoveram diferenças significativas da epiderme na face adaxial (Ead), na espessura do mesofilo (M) e na espessura do limbo foliar (L). As folhas em secção transversal apresentaram epiderme unisseriada em ambas as faces e clorênquima homogêneo com células isodiamétricas (Figura 1).

Plantas cultivadas sob malha azul em sala de crescimento e casa de vegetação apresentaram aumento do tamanho das células da epiderme na face adaxial (31,73 e 35,46 $\mu \mathrm{m})$, respectivamente, quando comparado com os demais tratamentos, na ausência de malha, malha vermelha e malha preta. Isso, possivelmente, ocorreu em função da maior atividade da enzima fenilalanina amônia-liase, aumentando a biossíntese de lignina, causando maior espessamento das paredes das células epidérmicas, sob o espectro azul (TAIZ; ZEIGER, 2009) (Tabela 1).

A qualidade espectral afeta a anatomia das folhas, parecendo exercer maiores efeitos durante a expansão foliar, exibindo alto grau de plasticidade durante a aclimatização, tanto anatômico como fisiológico ((DIGNART et al., 2009). Esse efeito é de fundamental importância, por proporcionar menor taxa de transpiração cuticular nas folhas, o que aumenta as chances de sobrevivência das plantas no ambiente $e x$ vitro. $\mathrm{O}$ aumento da espessura das células da epiderme na face adaxial de plantas sombreadas com malha azul foi de $26,15 \%$, em casa de vegetação, e de $11,8 \%$, em sala de crescimento, conforme apresentado na figura 1 (Tabela 1).

Aumentos na espessura do mesofilo foram influenciados pelo sombreamento com malha azul em casa de vegetação $(100,97 \mu \mathrm{m})$ em até $20 \%$ maior quando comparado com os demais tratamentos. Por tratar-se de uma planta esciófita, níveis de sombreamento são necessários para diferenciação dos tecidos. Segundo MARTINS et al. (2009), utilizando malhas coloridas no cultivo de Ocimum gratissimum, os autores verificaram que o tratamento a pleno sol promoveu maior espessamento do mesofilo e maior quantidade de tricomas glandulares, quando comparados com os tratamentos com malhas fotoconversoras azul, vermelha e preta, por tratar-se de uma planta heliófita.

Outra característica avaliada no presente trabalho foi à densidade estomática, considerada com alta plasticidade em decorrência da exposição das plantas a diferentes ambientes. Houve diferenças significativas entre as malhas coloridas e o ambiente. Em sala de crescimento com radiação de $52 \mathrm{w} \mathrm{m}^{-2} \mathrm{~s}^{-1}$, o número de estômatos por $\mathrm{mm}^{2}$ foi maior $(101,6)$ quando

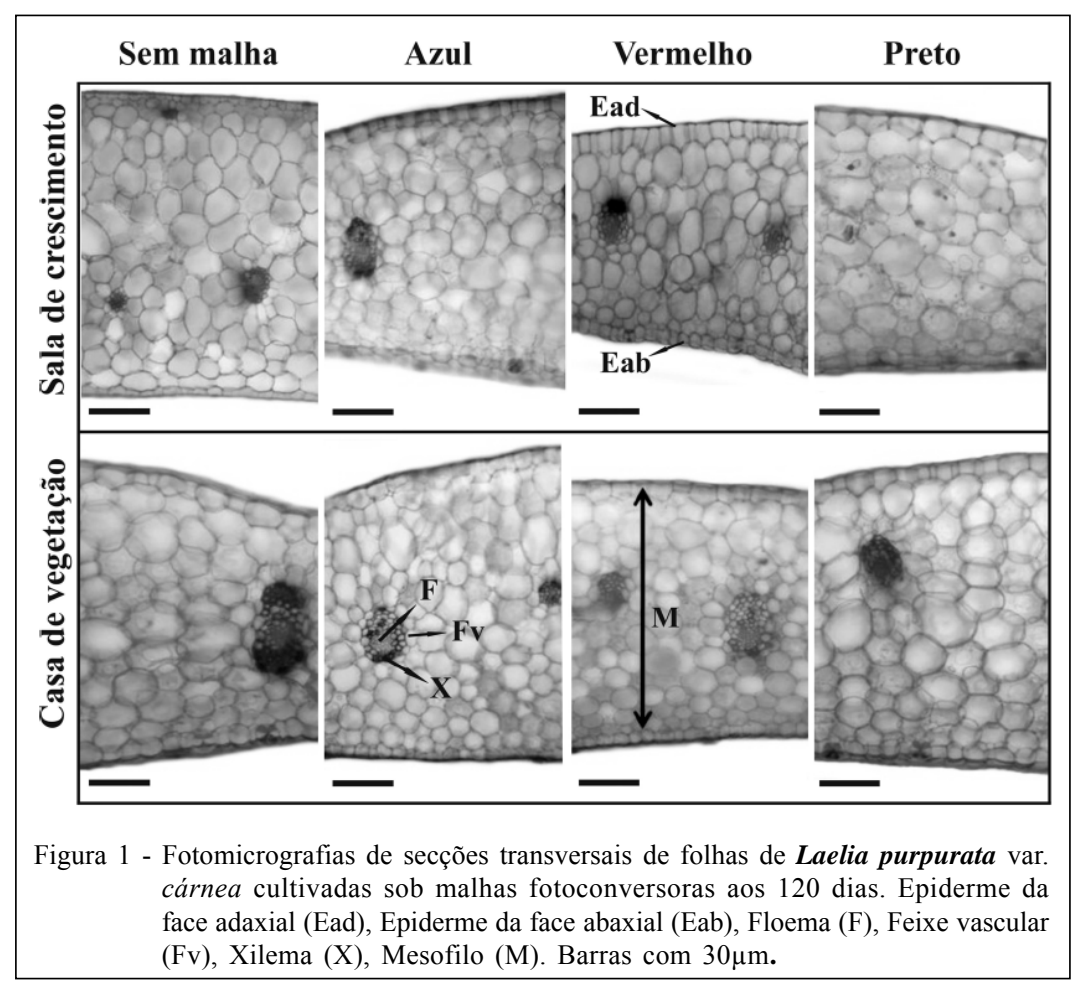

Ciência Rural, v.42, n.3, mar, 2012. 
Tabela 1 - Espessura dos tecidos e do limbo foliar de Laelia purpurata var. cárnea propagadas in vitro em diferentes ambientes e malhas coloridas. Epiderme na face adaxial (Ead), Epiderme na face abaxial (Eab), Espessura do mesofilo (M), Espessura do limbo foliar (L).

\begin{tabular}{|c|c|c|c|c|c|}
\hline Ambientes & Malhas & $\operatorname{Ead}(\mu \mathrm{m})$ & $\mathrm{Eab}(\mu \mathrm{m})$ & $\mathrm{M}(\mu \mathrm{m})$ & $\mathrm{L}(\mu \mathrm{m})$ \\
\hline \multirow{4}{*}{ Sala de crescimento } & Sem malha & $28,01 \mathrm{bA}$ & $23,98 \mathrm{aA}$ & $81,32 \mathrm{cB}$ & $134,97 \mathrm{bA}$ \\
\hline & Azul & $31,73 \mathrm{aB}$ & $23,34 \mathrm{aA}$ & $99,37 \mathrm{aB}$ & $151,33 \mathrm{aA}$ \\
\hline & Vermelho & $29,07 \mathrm{bA}$ & $22,76 \mathrm{aA}$ & $94,38 \mathrm{bB}$ & $147,82 \mathrm{bA}$ \\
\hline & Preto & $27,87 \mathrm{bA}$ & $22,01 \mathrm{aA}$ & $92,86 \mathrm{bA}$ & $144,7 \mathrm{bA}$ \\
\hline \multirow{4}{*}{ Casa de vegetação } & Sem malha & $29,73 \mathrm{bA}$ & $23,72 \mathrm{aA}$ & $93,38 \mathrm{bA}$ & $148,97 \mathrm{bA}$ \\
\hline & Azul & $35,46 \mathrm{aA}$ & $22,59 \mathrm{aA}$ & $100,97 \mathrm{aA}$ & $171,74 \mathrm{aA}$ \\
\hline & Vermelho & $29,07 \mathrm{bA}$ & $21,76 \mathrm{aA}$ & $100,08 \mathrm{aA}$ & $157,01 \mathrm{bA}$ \\
\hline & Preto & $28,08 \mathrm{bA}$ & $22,89 \mathrm{aA}$ & $99,91 \mathrm{bA}$ & $152,5 \mathrm{bA}$ \\
\hline CV $(\%)$ & & 8,91 & 17,63 & 11,08 & 21,86 \\
\hline Erro padrão & & 1,88 & 2,32 & 4,76 & 1,69 \\
\hline
\end{tabular}

Teste de Tukey a 5\% de significância. Letras minúsculas comparam os tratamentos dentro dos ambientes, enquanto que as letras maiúsculas comparam entre os ambientes.

aplicado malha vermelha. Já em casa de vegetação sem cobertura de malha com radiação $256 \mathrm{w} \mathrm{m}^{-2} \mathrm{~s}^{-1}$, o valor foi de $(254,85)$ estômatos por $\mathrm{mm}^{2}$, seguido de malha azul $(162,21)$ e vermelha $(157,93)$ que não diferiram estatisticamente.

Desse modo, pode-se inferir que a radiação auxiliou na modulação da densidade estomática nos ambientes. Quando utilizado malha vermelha em sala de crescimento, por se tratar de uma planta esciófita, ela não estava em condição de estresse luminoso. Entretanto, as plantas mantidas em casa de vegetação sob intensidade luminosa quatro vezes maior, possivelmente teve aumento em sua taxa transpiratória, o que induziu o aumento da densidade estomática (DIGNART et al., 2009), conforme a tabela 2.

Quanto ao diâmetro polar (P), equatorial (E) e a relação destes $(\mathrm{P} / \mathrm{E})$, houve diferença significativa para $(\mathrm{P})$ e $(\mathrm{P} / \mathrm{E})$ para plantas cultivadas em casa de vegetação, em ralação às cultivadas em sala de crescimento (Tabela 2). Tais observações podem ser atribuídas ao aumento da radiação sobre as plantas mantidas em casa de vegetação (LARCHER, 2004).

As paredes anticlinais das células ordinárias da epiderme na face abaxial se apresentaram sinuosas

Tabela 2- Quantificação de estômatos e medição dos diâmetros na face abaxial foliar de Laelia purpurata var. cárnea cultivados in vitro e submetidas aos diferentes ambientes e malhas coloridas. Número de estômatos por $\mathrm{mm}^{2}$ (n. estômatos $\mathrm{mm}^{-2}$ ), diâmetro polar (P), diâmetro equatorial (E) e relação (P/E).

\begin{tabular}{llclll}
\hline Ambientes & Malhas & (n. estômatos mm m $^{-2}$ & $\mathrm{P}(\mu \mathrm{m})$ & $\mathrm{E}(\mu \mathrm{m})$ & $\mathrm{P} / \mathrm{E}$ \\
\hline & Sem malha & $93,89 \mathrm{bB}$ & $41,23 \mathrm{aB}$ & $29,31 \mathrm{aA}$ & $1,46 \mathrm{aB}$ \\
& Azul & $98,92 \mathrm{bB}$ & $40,31 \mathrm{aB}$ & $30,87 \mathrm{aA}$ & $1,31 \mathrm{aB}$ \\
Sala de crescimento & $101,6 \mathrm{aB}$ & $40,45 \mathrm{aB}$ & $28,44 \mathrm{aA}$ & $1,42 \mathrm{aB}$ \\
& Vermelho & $86,68 \mathrm{cB}$ & $42,01 \mathrm{aB}$ & $27,78 \mathrm{aA}$ & $1,51 \mathrm{aB}$ \\
& Preto & & & $30,0 \mathrm{aA}$ & $1,76 \mathrm{aA}$ \\
& & $254,85 \mathrm{aA}$ & $52,92 \mathrm{aA}$ & $30,23 \mathrm{aA}$ & $1,74 \mathrm{aA}$ \\
& Sem malha & $162,21 \mathrm{bA}$ & $52,65 \mathrm{aA}$ & $33,11 \mathrm{aA}$ & $1,61 \mathrm{aA}$ \\
Casa de vegetação & Azul & $157,93 \mathrm{bA}$ & $53,22 \mathrm{aA}$ & $32,51 \mathrm{aA}$ & $1,68 \mathrm{aA}$ \\
& Vermelho & $96,02 \mathrm{cA}$ & $54,87 \mathrm{aA}$ & & 6,31 \\
CV (\%) & Preto & 12,8 & & 10,28 & 2,43 \\
Erro padrão & & 10,42 & 4,87 & \\
\hline
\end{tabular}

Tukey, a 5\% de significância. Letras minúsculas comparam os tratamentos dentro dos ambientes, enquanto que as letras maiúsculas comparam entre os ambientes.

Ciência Rural, v.42, n.3, mar, 2012. 
nos tratamentos em sala de crescimento, e estômatos do tipo anomocítico, com os ostíolos abertos. Conseqüentemente, o diâmetro polar foi menor que o das plantas em casa de vegetação. As plantas em sala de crescimento apresentaram maior densidade estomática quando sombreadas com malha vermelha. Já em ambiente de casa de vegetação, o maior índice foi registrado no tratamento sem a presença de malha (Tabela 2). Quanto maior a relação diâmetro polar/ equatorial (P/E), mais elipsoide é o formato do estômato, portanto, maior funcionalidade ele deve apresentar (MARTINS et al., 2009).

Foi observada exoderme unisseriada nas raízes de plantas cultivadas em ambos os ambientes e formação de idiobastos na exoderme em raízes de plantas cultivadas em sala de crescimento (Figura 2).

Enquanto que em casa de vegetação o tamanho e a morfologia das células da exoderme se apresentaram homogêneas e isodiamétricas (Figura 3), houve aumento significativo no número de camadas de células do velame, em raízes de plantas cultivadas em sala de crescimento e casa de vegetação sob malha azul.

Neste ambiente, o cultivo com malha azul $(105,15 \mu \mathrm{m})$ não diferiu estatisticamente da malha preta
$(101,03 \mu \mathrm{m})$, sendo os maiores valores observados. Sendo assim, podemos inferir que existe efeito da malha e do ambiente no crescimento e desenvolvimento do sistema radicular de Laelia purpurata var. cárnea (TAIZ; ZEIGER, 2009) (Tabela 3).

Embora as plantas tenham sido mantidas in vitro, as condições de iluminação na casa de vegetação proporcionaram desenvolvimento mais uniforme do velame, cuja função é a captação da umidade do ar, transformando o estado físico da água de gasoso para líquido nas células da exoderme, passando pelo córtex, e posteriormente ao cilindro vascular, finalmente distribuída por toda planta.

$\mathrm{O}$ acondicionamento limitante das plantas em sala de crescimento, em especial a radiação e temperatura, podem ter sido os fatores que provocaram a menor diferenciação das camadas do velame (MAYER et al., 2008). Porém, as plantas mantidas em casa de vegetação com radiação e temperatura maior, apresentaram maior grau de diferenciação dos tecidos radiculares (Tabela 3 ).

Portanto, o ambiente de casa de vegetação com malha azul ou preta possibilita o desenvolvimento uniforme do velame, permitindo assim uma melhor

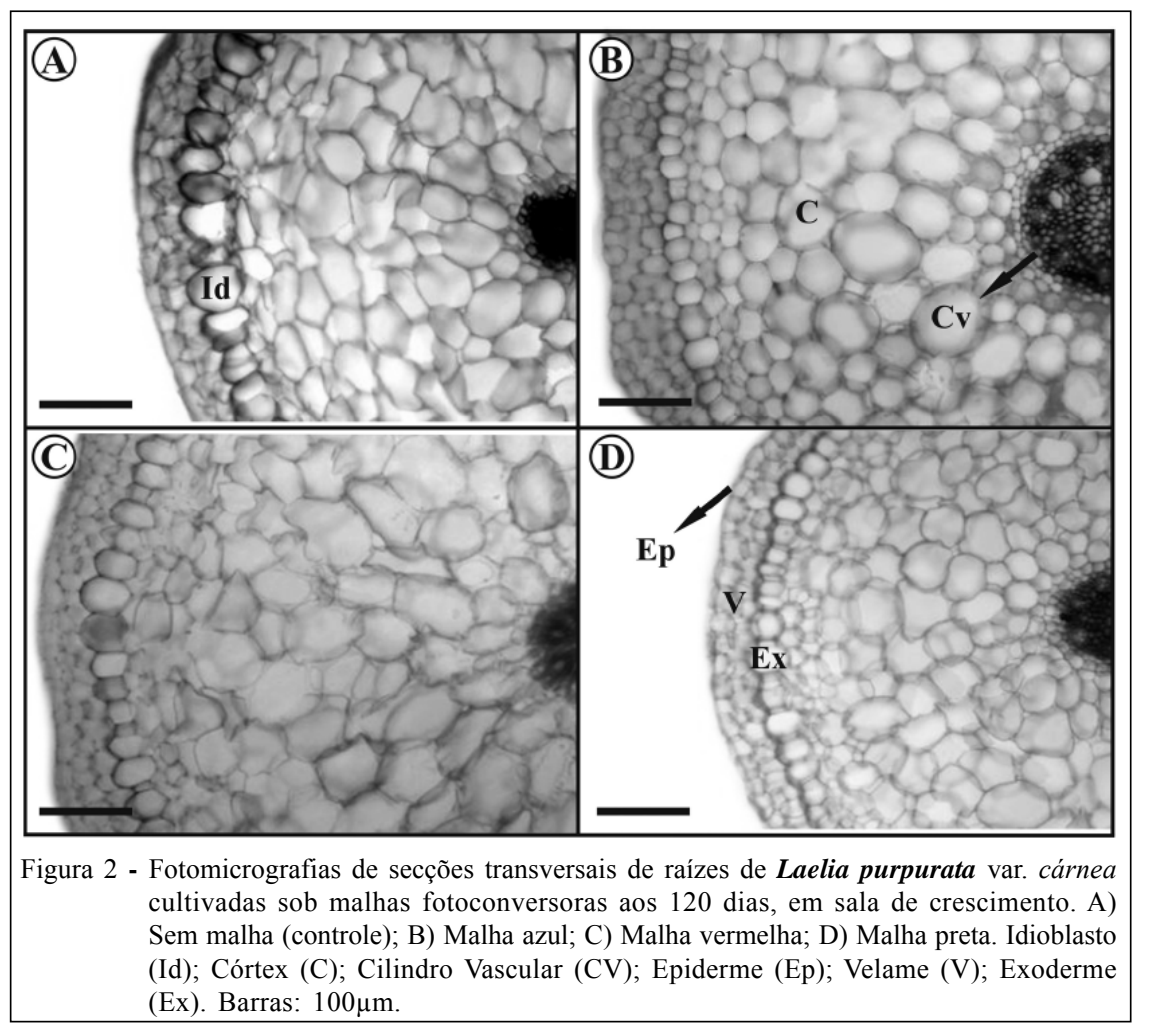

Ciência Rural, v.42, n.3, mar, 2012. 


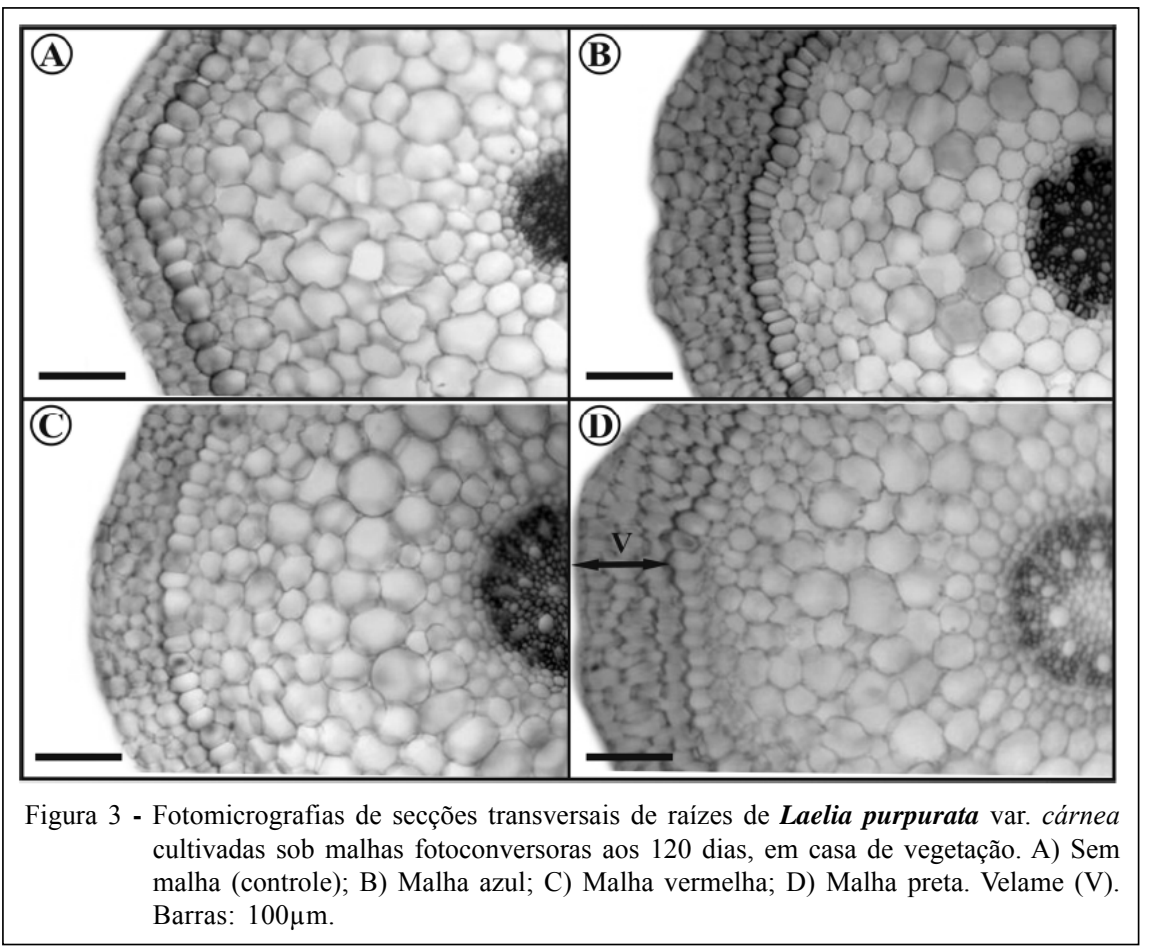

adaptação dessas plantas ao ambiente ex vitro. A espessura da exoderme apresentou diferenças significativas quanto ao ambiente de cultivo e qualidade da luz fornecida pelas malhas fotoconversoras (Tabela 3).

Segundo os autores MAYER et al. (2008), corte transversal de raiz de orquídeas em condições naturais, apresentam características típicas da família Orchidaceae, como velame constituído por nove camadas de células, córtex com exoderme e endoderme bem definidas e cilindro vascular poliarco. As células da exoderme possuem paredes periclinais externas e anticlinais espessadas, estando alternadas com células de passagem.

A exoderme é importante como uma barreira apoplástica ao refluxo de água e entrada de patógenos. Durante as fases do cultivo in vitro, as plantas crescem

Tabela 3 - Características quantitativas dos tecidos radiculares de plantas de Laelia purpurata var. cárnea, em diferentes ambientes e malhas coloridas. Velame (V), Exoderme (Ex), Córtex (Co) e Cilindro vascular (Cva).

\begin{tabular}{llllll}
\hline Ambientes & Malhas & $\mathrm{V}(\mu \mathrm{m})$ & $\operatorname{Ex}(\mu \mathrm{m})$ & $\mathrm{Co}(\mu \mathrm{m})$ & $\mathrm{Cva}(\mu \mathrm{m})$ \\
\hline & Sem malha & $37,03 \mathrm{cB}$ & $33,47 \mathrm{aA}$ & $270,56 \mathrm{bB}$ & $73,98 \mathrm{bB}$ \\
& Azul & $75,85 \mathrm{aA}$ & $30,09 \mathrm{aA}$ & $330,81 \mathrm{aA}$ & $139,01 \mathrm{aB}$ \\
Sala de crescimento & Vermelho & $49,01 \mathrm{bB}$ & $33,71 \mathrm{aA}$ & $390,54 \mathrm{aA}$ & $100,72 \mathrm{aB}$ \\
& Preto & $36,54 \mathrm{cB}$ & $30,99 \mathrm{aA}$ & $260,21 \mathrm{bB}$ & $79,35 \mathrm{bB}$ \\
& & & & & \\
& Sem malha & $50,56 \mathrm{cA}$ & $29,33 \mathrm{bB}$ & $330,79 \mathrm{aA}$ & $91,04 \mathrm{cA}$ \\
& Azul & $105,15 \mathrm{aA}$ & $28,71 \mathrm{bB}$ & $260,58 \mathrm{bB}$ & $169,60 \mathrm{aA}$ \\
& Vermelho & $80,11 \mathrm{bA}$ & $29,42 \mathrm{bB}$ & $315,99 \mathrm{aB}$ & $149,69 \mathrm{bA}$ \\
Casa de vegetação & Preto & $101,03 \mathrm{aA}$ & $27,76 \mathrm{bB}$ & $310,71 \mathrm{aA}$ & $159,97 \mathrm{bA}$ \\
& & & & & 8,92 \\
CV (\%) & & 10,32 & 3,55 & 6,81 & 5,24 \\
Erro padrão & & 2,14 & 1,64 & 4,72 & \\
\hline
\end{tabular}

Teste Tukey, a 5\% de significância. Letras minúsculas comparam os tratamentos dentro dos ambientes, enquanto que as letras maiúsculas comparam entre os ambientes. 
sob condições de saturação de vapor d'agua, baixa incidência de fótons fotossinteticamente ativos, e utilizam a sacarose como fonte de carbono, que, por sua vez, é altamente assimilável (CASTRO, 2009).

Dessa forma, a baixa diferenciação da exoderme de Laelia purpurata var. cárnea em condições in vitro pode estar relacionada com a elevada umidade relativa do ambiente, necessitando de um período de aclimatização, devido a sua baixa funcionalidade (MAYER et al., 2008; CASTRO et al., 2009).

O córtex das plantas cultivadas em casa de vegetação apresentou menor diâmetro e células de menor tamanho, quando comparado com o de plantas mantidas em sala de crescimento. Neste ambiente, a menor radiação e temperatura constante favoreceram maior retenção de água no interior das células, deixandoas mais túrgidas na ausência de malha (Figura 2A) e sob malha vermelha (Figura 2C).

As plantas desenvolvidas em casa de vegetação na presença de malhas apresentaram os maiores diâmetros do cilindro vascular (CVa) (Figura 3). Possivelmente, nesse ambiente de maior radiação difusa e maior temperatura, tais fatores favoreceram maior diferenciação de xilema e floema.

\section{CONCLUSÃO}

As plantas cultivadas em casa de vegetação apresentaram: maior espessura de velame na raiz, maior espessura da epiderme, maior densidade estomática e maior espessura do mesofilo na folha. Com isso, é possível concluir que plantas cultivadas em casa de vegetação são mais adequadas para cultivo in vitro e posterior cultivo ex vitro, quando comparadas com plantas cultivadas em sala de crescimento.

\section{REFERÊNCIAS}

ÁVILA-DIAZ, I. et al. In vitro propagation of the endangered orchid Laelia speciosa. Plant Cell, Tissue and Organ Culture, v.99, n.3, p.335-343, 2009. Disponível em: <http://images3.wikia.nocookie.net/ cb20100215065348/orchids/en/images/b/bf/ In_vitro_propagation_of the_endangered_orchid_Laelia_speciosa.pdf $\$$. Acesso em: 27 nov. 2011. doi: 10.1007/s11240-009-9609-8.

BRAGA, F.T. et al. Qualidade de luz no cultivo in vitro de Dendranthema grandiflorum cv. Rage: características morfofisiológicas. Ciência e Agrotecnologia, v.33, n.2, p.502-508, 2009. Disponível em: <http://www.scielo.br/ scielo.php?script=sci_arttext\&pid=S 1413 $70542009000200022>$. Acesso em: 12 mar. 2011. doi: 10.1590/S1413-70542009000200022.

CASTRO, E.M. et al. Histologia vegetal: estrutura e função de órgãos vegetativos. Lavras: UFLA, 2009. 234p.

CRUZ, C.D. GENES - Software for experimental statistics in genetics. Genetics and Molecular Biology [online], v.21, p.1, 1998.

DIGNART, S.L. et al. Luz natural e concentrações de sacarose no cultivo in vitro de Cattleya walkeriana. Ciência e
Agrotecnologia, v.33, n.3, p.780-787, 2009. Disponível em: $<$ http://www.scielo.br/scielo.php?script=sci_arttext\&pid=S141370542009000300017>. Acesso em: 30 nov. 2011. doi: http:// dx.doi.org/10.1590/S1413-70542009000300017.

JOHANSEN, D.A. Plant microtechnique. New York: Mc Graw-Hill Book, 1940. 423p.

LARCHER, W. Ecofisiologia vegetal. São Carlos: Rima Artes e Textos, 2004. 531p.

MARTINS, J.R. et al. Anatomia foliar de plantas de alfavaca-cravo cultivadas sob malhas coloridas. Ciência Rural, v.39, n.1, p.8287, 2009. Disponível em: <http://www.scielo.br/ scielo.php?pid $=$ S0103-84782009000100013\&script $=$ sci_arttext $>$. Acesso em: 21 fev. 2011. doi: $10.1590 / \mathrm{S} 0103-$ 84782008005000040 .

MAYER, J.L.S. et al. Anatomia comparada das folhas e raízes de Cymbidium Hort. (Orchidaceae) cultivadas ex vitro e in vitro. Acta Botanica Brasílica, v.22, n.2, p.323-332, 2008. Disponível em: <http://www.scielo.br/scielo.php?pid=S0102$33062008000200003 \&$ script $=$ sci arttext $>$. Acesso em: 14 jun. 2011. doi: $10.1590 / \mathrm{S} 0102-33062008000200003$.

METCALfe, C.R.; CHALK, L. Anatomy of the dicotyledons: systematic anatomy of the leaf and stem. 2.ed. New York: Oxford University, 1979. V.1.

MURASHIGE, T.; SKOOG, F.A. A revised medium for rapid growth and bioassay with tabacco tissue culture. Physiologia Plantarum, v.25, p.473-497, 1962. Disponível em: <http:// onlinelibrary.wiley.com/doi/10.1111/j.13993054.1962.tb08052.x/abstract>. Acesso em: 23 nov. 2010. doi: $10.1111 / \mathrm{j} .1399-3054.1962 . t b 08052 . x$.

OREN-SHAMIR, M. et al. Coloured shade nets can improve the yield and quality of green decorative branches of Pittosphorum variegatum. Journal of Horticultural Science and Biotechnology, v.76, n.3, p.353-361, 2001. Disponível em: <http://www.scopus.com/results/results.url?sort=plf$\mathrm{f} \& \mathrm{src}=\mathrm{s} \& \mathrm{st} 1=$ Coloured + shade + nets + can + improve + the + yield + and + quality \&sid=pwqQF $-45 \mathrm{CY}$ xbVL2ZgeeZAO $4 \% 3$ a $340 \&$ $\mathrm{s}$ o $\mathrm{t}=\mathrm{b} \& \mathrm{sdt}=\mathrm{b} \& \mathrm{~s} 1=73 \& \mathrm{~s}=\mathrm{T}$ I T LE - A B S - K E Y AUTH $\% 28$ Coloured + shade+nets + can + improve + the + yield + and + quality $\%$ $29 \&$ or ig i n $=$ se a r c h b a si c \& t x G i d = p w q Q F 45CYxbVL2ZgeeZAO4\%3a34>. Acesso em: 10 set. 2010.

PASQUAL, M. et al. Influência da qualidade de luz e silício no crescimento in vitro de orquídeas nativas e híbridas. Horticultura Brasileira, v.29, p.324-329, 2011. Disponível em: $<$ http:// w w w. s c i e 1 o.b r/s c i e 1 o.ph p ? p id = S 0102 05362011000300011\&script=sci arttext $>$. Acesso em: 30 nov. 2011. doi: http://dx.doi.org/10.1590/S0102-05362011000300011.

PEREIRA, F.J. et al. Evolução da anatomia radicular do milho 'Saracura' em ciclos de seleção sucessivos. Pesquisa Agropecuária Brasileira, v.43, n.12, p.1649-1656, 2008. Disponível em: $<$ http://www.scielo.br/scielo.php?script=sci_arttext\&pid=S0100$204 X 2008001200002 \& \operatorname{lng}=$ pt\&nrm=iso $>$. Acesso em: 30 nov. 2011. doi: http://dx.doi.org/10.1590/S0100-204X2008001200002.

SHAHAK, Y. et al. Colornets: crop protection and light-quality manipulation in one technology. Acta Horticulturae, n.659, p.143151, 2004. Disponível em: <http://www.ufrb.edu.br/nutricaomineral/ nmp pg 09/ColorNets\%20Crop\%20Protection\%20and\%20LightQuality\%20Manipulation\%20in\%20One\%20technology\%20\%20shahak.pdf>. Acesso em: 18 jan. 2011.

TAIZ, L.; ZEIGER, E. Fisiologia vegetal. 5.ed. Porto Alegre: Artmed, 2009. 848 p.

Ciência Rural, v.42, n.3, mar, 2012. 